\title{
Lung macrophages drive mucus production and steroid-resistant inflammation in chronic bronchitis
}

\author{
Kristina Andelid ${ }^{1,2}$, Karolina Öst $^{3}$, Anders Andersson $^{1,2}$, Esha Mohamed ${ }^{4}, Z_{\text {Zala Jevnikar }}^{5}$, \\ Lowie E. G. W. Vanfleteren ${ }^{1,2}$ (10 and Melker Göransson ${ }^{3^{*}}$ (0)
}

\begin{abstract}
Background: Patients with chronic obstructive pulmonary disease (COPD) frequently suffer from chronic bronchitis (CB) and display steroid-resistant inflammation with increased sputum neutrophils and macrophages. Recently, a causal link between mucus hyper-concentration and disease progression of CB has been suggested.

Methods: In this study, we have evaluated the steroid sensitivity of purified, patient-derived sputum and alveolar macrophages and used a novel mechanistic cross-talk assay to examine how macrophages and bronchial epithelial cells cross-talk to regulate MUC5B production.

Results: We demonstrate that sputum plug macrophages isolated from COPD patients with chronic bronchitis (COPD/CB) are chronically activated and only partially respond to ex vivo corticosteroid treatment compared to alveolar macrophages isolated from lung resections. Further, we show that pseudo-stratified bronchial epithelial cells grown in air-liquid-interface are inert to direct bacterial lipopolysaccharide stimulation and that macrophages are able to relay this signal and activate the CREB/AP-1 transcription factor complex and subsequent MUC5B expression in epithelial cells through a soluble mediator. Using recombinant protein and neutralizing antibodies, we identified a key role for TNFa in this cross-talk.
\end{abstract}

Conclusions: For the first time, we describe ex vivo pharmacology in purified human sputum macrophages isolated from chronic bronchitis COPD patients and identify a possible basis for the steroid resistance frequently seen in this population. Our data pinpoint a critical role for chronically activated sputum macrophages in perpetuating TNFadependent signals driving mucus hyper-production. Targeting the chronically activated mucus plug macrophage phenotype and interfering with aberrant macrophage-epithelial cross-talk may provide a novel strategy to resolve chronic inflammatory lung disease.

Keywords: COPD, Chronic bronchitis, Sputum macrophages, Steroid resistance, TNFa, MUC5B, Macrophageepithelial cross-talk

\footnotetext{
*Correspondence: Melker.Goransson@AstraZeneca.com

${ }^{3}$ Department of Bioscience COPD/IPF, Research and Early Development,

Respiratory and Immunology (R\&l), BioPharmaceuticals R\&D, AstraZeneca, Pepparedsleden 1, 43153 Gothenburg, Sweden

Full list of author information is available at the end of the article
}

\section{Background}

Chronic obstructive pulmonary disease (COPD) is now well recognized to be a heterogeneous disease with a spectrum of different phenotypes at the clinical level and endotypes at the biological level. A subset of patients with COPD show increased eosinophils in blood and a favorable response to corticosteroids [1]. original author(s) and the source, provide a link to the Creative Commons licence, and indicate if changes were made. The images or other third party material in this article are included in the article's Creative Commons licence, unless indicated otherwise in a credit line to the material. If material is not included in the article's Creative Commons licence and your intended use is not permitted by statutory regulation or exceeds the permitted use, you will need to obtain permission directly from the copyright holder. To view a copy of this licence, visit http://creativecommons.org/licenses/by/4.0/. The Creative Commons Public Domain Dedication waiver (http://creativeco mmons.org/publicdomain/zero/1.0/) applies to the data made available in this article, unless otherwise stated in a credit line to the data. 
However, the most common phenotype of COPD displays an increased number of neutrophils in sputum reflecting a neutrophilic lung disease. This neutrophilic phenotype responds poorly to corticosteroids and there is an urgent need to find new ways to treat this group of patients [2].

Chronic bronchitis (CB) is a constant inflammation of the lining of the bronchial tubes resulting in hypertrophy of the mucus-producing glands found in the mucosa of large cartilaginous airways and epithelial surface goblet cell hyperplasia in the central airways. Among COPD patients, CB occurs in 14-74\% of cases, depending on the particular definition used [3].

$\mathrm{CB}$ is most commonly defined epidemiologically as cough and sputum production for $\geq 3$ months for at least 2 consecutive years [4]. Patients with both COPD and $\mathrm{CB}$ exhibit mucin hyper-expression (5) which lead to mucus hyper-concentration, increased viscosity and subsequently to an impaired mucus clearance and persistent neutrophil airway inflammation and bacterial colonization [6]. Therefore, subjects with CB experience more exacerbations, an increased risk of accelerated decline in lung function and decreased survival [7].

The major macromolecular components of the mucus in human airways are the mucin glycoproteins MUC5B and MUC5AC [8-10]. In the healthy lung, MUC5AC is mainly produced by epithelial surface goblet cells found in both large and small airways, whereas MUC5B is predominantly secreted from mucus cells in submucosal glands of the large trachea and the bronchial tubes [10, 11]. However, in patients with inflammatory airway diseases including COPD, MUC5B is also upregulated in airway epithelium in both large and small airways [1214]. Thus, the pathological changes in the airway epithelia lead to persistent elevated secretion of mucus from epithelial goblet cells into the respiratory tract, including distal airways [15].

In $\mathrm{COPD} / \mathrm{CB}$, macrophages are believed to play a major role in orchestrating the inflammatory response [16]. Together with epithelial cells and the mucus layer, they constitute the first line of defense against infections and noxious agents. Although the number of alveolar macrophages is increased in bronchoalveolar lavage (BAL) from healthy smokers [17], and from both current and ex-smoking COPD patients [18], a vast body of evidence suggest that these cells are functionally impaired with reduced ability to release pro-inflammatory cytokines in response to bacterial lipopolysaccharides (LPS) [19-22]. In contrast to these findings, the levels of macrophagederived pro-inflammatory mediators such as TNF- $\alpha$, CCL3 and IL1 $\beta$ are reported to be strongly increased in sputum from both current and ex-smoking COPD patients [2]. This apparent discrepancy suggests specific chronic activation of macrophages in sputum rather than a general chronic activation of lung macrophages.

Neutrophilia is a key feature of chronic bronchitis and a complex network of cytokines and chemokines including IL-8 (CXCL8), CXCL1/5/7 and CCL3 are known chemotactic factors for neutrophil migration to inflammatory sites through binding to CXCR $1 / 2$ and CCR $1 / 5$ receptors [23-25]. Further, inflammasome-activated IL1 $\beta$ has been shown to drive neutrophil influx through an IL-8 independent mechanism in vivo [26] and in vitro exposure to TNF $\alpha$ has been shown to increase the ability of human neutrophils to migrate towards CCL3 through CCR5-mediated activity [27]. Thus, TNF $\alpha$, CCL3 and IL1 $\beta$, which are found in high concentrations in sputum, can all influence neutrophil recruitment as well as sustain the inflammatory process in neutrophilic lung disease.

Even though the clinical manifestations of $\mathrm{CB}$ are well characterized, little is known about the underlying signaling driving sputum hyper-production and the contribution of different cell types to the clinically observed corticosteroid resistance in this chronic inflammatory disease. We hypothesized that the highly neutrophilic and pro-inflammatory cytokine milieu in sputum plugs may drive development of a steroid-resistant, chronically activated macrophage phenotype that constantly secretes inflammatory signals driving mucus hyper-production by epithelial cells.

In this study, we aimed to investigate the nature of macrophage-epithelial signaling driving mucus hyperproduction using a newly established mechanistic in vitro model and to compare the LPS and steroid responsiveness of clinically sampled macrophages isolated from sputum plugs from patients with COPD and chronic bronchitis to that of alveolar macrophages isolated from lung resection tissue. Some of the results of these studies have been previously reported in the form of abstracts $[28,29]$.

\section{Materials and methods \\ Sampling of sputum macrophages Study design and patients}

The current analysis was part of an exploratory study of inflammatory responses in blood and cells isolated from induced sputum from COPD/CB patients, an observational single-center study. This study was conducted in accordance with the amended Declaration of Helsinki and approved by the ethics committee at the University of Gothenburg, Sweden, Approval number 501-17 and T 820-17. Written informed consent was obtained from all patients.

Patients with $\mathrm{CB}$, defined as a history of cough with sputum expectoration for at least 3 months a year during a period of 2 consecutive years, ascertained 
by oral interview and questionnaires were included in the study. Patients with COPD (GOLD I-III) aged 60-73 years, in a clinically stable state, were prospectively recruited between September 2017 and March 2018 at the COPD Centre at Sahlgrenska University Hospital, Sweden. Patients currently on PDE4 inhibitors or systemic glucocorticosteroids were excluded from the study.

Sixteen patients were recruited into the study and all were successful in producing induced sputum. However, there were only 9 patients, where we were able to isolate sufficient numbers of viable sputum macrophages to study LPS and/or steroid responsiveness in technical triplicates $\left(>0.8 \times 10^{6}\right.$ cells $)$, that were included in the current analyses (Table 1).

\section{Assessments}

All patients underwent physical examination, including demographic information, medication history and smoking status at the inclusion visit. CAT (COPD assessment test) was performed [30] and a short $\mathrm{CB}$ questionnaire (Additional file 1: Table S1) to assure active CB phenotype. All patients performed spirometry (IntraMed, LaunchSentrySuite) and a pulmonary $\mathrm{x}$-ray.

At the second visit, within 3 weeks after the inclusion visit, induced sputum and blood samples were collected. Five millilitre of peripheral venous blood was sampled for analyses of white blood cell differential tests and highsensitive $\mathrm{C}$-reactive protein (CRP) at the Department of Clinical Chemistry, Sahlgrenska University Hospital (Table 2).

Table 1 Subject characteristics of sputum donors

\begin{tabular}{|c|c|c|c|c|c|c|c|c|c|c|c|}
\hline \multicolumn{8}{|c|}{ Clinical data } & \multicolumn{4}{|c|}{ Ex vivo assays } \\
\hline Patient & Age span & Pack years & FEV1 (L) & FEV $1 \%$ of pred & FEV1/FVC (\%) & CAT $^{C}$ & $\overline{C B-Q^{d}}$ & qPCR TNF & qPCR ILIB & qPCR CCL3 & $\begin{array}{l}\text { Steroid } \\
\text { resistance }\end{array}$ \\
\hline 1 & $70-74$ & 50 & $2.6\left(3.1^{\mathrm{a}}\right)$ & $59\left(71^{a}\right)$ & $53\left(59^{a}\right)$ & 22 & 34 & $x$ & $x$ & & \\
\hline 2 & $70-74$ & 7 & 2.4 & 79 & 69 & 16 & 31 & $x$ & $x$ & & \\
\hline 3 & $70-74$ & 44 & 1.8 & 57 & 61 & 29 & 38 & $x$ & $x$ & & \\
\hline 4 & $60-64$ & 47 & $1.0\left(1.1^{\mathrm{a}}\right)$ & $39\left(44^{\mathrm{a}}\right)$ & $43\left(47^{a}\right)$ & 31 & 42 & $x$ & $x$ & $x$ & \\
\hline 5 & $70-74$ & 75 & 2.5 & 88 & 52 & 31 & 39 & $x$ & $x$ & $x$ & $x$ \\
\hline 6 & $60-64$ & $8^{b}$ & $4.3\left(4.3^{\mathrm{a}}\right)$ & $97(98)^{a}$ & $61\left(63^{a}\right)$ & 19 & 31 & & & & $x$ \\
\hline 7 & $65-69$ & 33 & $1.7\left(2.2^{\mathrm{a}}\right)$ & $44(56)^{a}$ & $46\left(51^{a}\right)$ & 16 & 27 & $x$ & $x$ & $x$ & $x$ \\
\hline 8 & $65-69$ & 47 & $1.5\left(1.4^{\mathrm{a}}\right)$ & $60\left(57^{a}\right)$ & $62\left(64^{a}\right)$ & 35 & 39 & $x$ & $x$ & $x$ & $x$ \\
\hline 9 & $65-69$ & 46 & $1.4\left(1.6^{a}\right)$ & $56(63)^{a}$ & $45\left(45^{a}\right)$ & 9 & 28 & $x$ & $x$ & $x$ & $x$ \\
\hline
\end{tabular}

a Spirometry with bronchodilation

${ }^{\mathrm{b}}$ Pipe

c COPD assessment test

${ }^{d}$ Chronic bronchitis questionnaire

Table 2 Inflammatory markers in blood

\begin{tabular}{|c|c|c|c|c|c|}
\hline Patient & CRP (mg/l) & Leukocytes $\left(\times 10^{9} / \mathrm{I}\right)$ & Neutrophils $\left(\times 10^{9} / \mathrm{I}\right)$ & Eosinophils (× 109/l) & $\begin{array}{l}\text { Lymphocytes } \\
\left(\times 10^{9} / I\right)\end{array}$ \\
\hline 1 & 1.4 & 9.3 & 2.8 & 0.2 & 5.7 \\
\hline 2 & $N / A^{a}$ & 7.9 & 5.3 & 0.1 & 2.0 \\
\hline 3 & 6.0 & 7.7 & 4.9 & 0.6 & 1.4 \\
\hline 4 & 3.2 & 7.1 & 3.7 & 0.1 & 2.9 \\
\hline 5 & 4.5 & 7.6 & 4.8 & 0.1 & 2.0 \\
\hline 6 & 1.0 & 7.9 & 5.1 & 0.4 & 1.8 \\
\hline 7 & 17 & 10 & 6.6 & 0.2 & 2.6 \\
\hline 8 & 1.9 & 6.8 & 4.9 & 0.2 & 1.1 \\
\hline 9 & 1.2 & 10 & 6.4 & 0.1 & 3.0 \\
\hline
\end{tabular}

${ }^{\mathrm{a}}$ Not available 


\section{Sputum induction}

Sputum induction through inhalation of hypertonic $\mathrm{NaCl}$ was performed using a standardized protocol [31] with some minor adjustments. Prior to induction, the baseline FEV1 (forced expiratory volume in $1 \mathrm{~s}$ ) was measured and patients with FEV $1<40 \%$ of predicted capacity were excluded to reduce the risk of adverse events. Patients were pre-medicated with inhaled Salbutamol $400 \mu \mathrm{g}$ and FEV1 was again measured. The nebulisation started with $3 \%$ hypertonic saline solution with an inhalation of 7 min (tidal breathing) followed by coughing and expectoration to harvest sputum samples. If the subject was not able to produce sputum the procedure was repeated using increased hypertonic saline solutions $(4 \%$ and $5 \% \mathrm{NaCl})$. FEV1 was measured after every round of inhalation. If FEV1 fell more than $20 \%$ from the post-salbutamol value or if the subject developed symptoms, the procedure was stopped. We used the Hedenström values, applying a non-linear age coefficient for lung function decline, as references for spirometry [32,33]. Sputum samples were put on ice and processed within $1 \mathrm{~h}$.

\section{Sampling of alveolar macrophages Study design and patients}

Alveolar macrophages (AM), were isolated from human lung resections from 7 patients with COPD and 10 patients without COPD, undergoing lung cancer resection surgery at the Department of Cardiothoracic Surgery at Sahlgrenska University Hospital. Clinical characteristics are presented in Additional file 2: Table S2. Samples were obtained in accordance with hospital and AstraZeneca ethical guidelines with written consent from all patients. Ethics committee Approval number 1026-15.
Studies on sputum and alveolar macrophages Sputum macrophage isolation and cell culture

Sputum macrophages (SM) were isolated from human induced sputum plugs by $5-10 \mathrm{~min}$ incubation in 4 volumes $(4 \times$ weight of plugs, final DTT concentration $=0.08 \%$ ) Sputolysin (Millipore) on an Intelli-mixer RM2S (ELMI) rotating vortex mixer (program F8 at $20 \mathrm{rpm}$ ) [31]. The sputum/Sputolysin mixture was inspected after $5 \mathrm{~min}$ and every minute thereafter to immediately proceed with the protocol as soon as the viscosity of the mixture changed drastically. The mixture was diluted to $0.04 \%$ DTT with cold PBS and filtered through a $70 \mu \mathrm{M}$ cell strainer, centrifuged at $300 g, 4{ }^{\circ} \mathrm{C}$ for $5 \mathrm{~min}$ and the sputum cell pellet was subsequently washed 3 times in $5 \mathrm{ml}$ cold PBS. A small portion of the sputum cells was transferred to glass slides by cytospin and stained with May-Grünwald Giemsa for differential counting (Table 3). More than 400 non-squamous cells from each sample were scored by two independent researchers and squamous cell count was $<10 \%$ in all samples, $1.8 \%(0.2-5.3)$, median (range). The sputum cell pellets were resuspended in warm Xvivo10 (Lonza \#BE04-743Q) supplemented with $2 \mathrm{mM} \mathrm{L}$-glutamine, $1 \times$ penicillin-streptomycin, $1.25 \mu \mathrm{g} / \mathrm{ml}$ Amphotericin B (all from Gibco, Life technologies) and seeded at a density of $1 \times 10^{5}$ cells/well in 96 well tissue culture treated microplates (Costar \#3595, Corning Inc.). The macrophage fraction was purified by attachment to cell culture plastics for $1 \mathrm{~h}$, followed by three repeated washes with $100 \mu \mathrm{l}$ warm Xvivo10 media to remove non-attaching cells such as neutrophils, eosinophils and lymphocytes. Treatment with $0.1 \%$ DMSO (Merck) or $50 \mathrm{nM}$ dexamethasone (Calbiochem) was performed overnight at $37{ }^{\circ} \mathrm{C}$ and $5 \%$ $\mathrm{CO}_{2}$. After overnight resting or compound or DMSO control treatment, the cells were either stimulated for $2 \mathrm{~h}$ (RNA isolation) or $6 \mathrm{~h}$ (measurement of soluble TNF $\alpha$ in

Table 3 Inflammatory cells in sputum

\begin{tabular}{|c|c|c|c|c|c|}
\hline \multirow[t]{2}{*}{ Patient } & \multicolumn{4}{|c|}{ Sputum cell composition (\%) } & \multirow{2}{*}{$\begin{array}{l}\text { Counts }\left(10^{6}\right)^{a} \\
\text { Total cells }\end{array}$} \\
\hline & Macrophages & Neutrophils & Eosinophils & Lymphocytes & \\
\hline 1 & 26.2 & 66.0 & 4.0 & 3.8 & 4.4 \\
\hline 2 & 12.2 & 82.3 & 1.5 & 3.9 & 9.8 \\
\hline 3 & 22.8 & 73.1 & 1.0 & 3.1 & 6.5 \\
\hline 4 & 14.1 & 83.2 & 1.2 & 1.5 & 7.6 \\
\hline 5 & 4.1 & 94.4 & 0.2 & 1.3 & 23.8 \\
\hline 6 & 10.0 & 63.7 & 25.4 & 0.9 & 10.7 \\
\hline 7 & 22.1 & 74.0 & 2.7 & 1.2 & 9.2 \\
\hline 8 & 9.8 & 86.9 & 0.5 & 2.8 & 10.2 \\
\hline 9 & 23.1 & 74.5 & 0.6 & 1.8 & 4.4 \\
\hline
\end{tabular}

${ }^{a}$ Non-squamous cells. Squamous cell count $<10 \%$ in all samples, $1.8 \%(0.2-5.3)$, median (range) 
media) with $100 \mathrm{ng} / \mathrm{ml}$ LPS (E. coli, clone 0127:B8, Sigma \#L4516). Macrophage viability, monitored in replicate wells at the end of the in vitro assays, was $83 \%$ (81-88), median (range). The purity of the culture after purification of macrophages by attachment was monitored by differential staining during the setup of the method ( $>90 \%, n=3$ ). During the study, the purity of the washed culture was monitored by visual inspection of cell morphology. A similar protocol for adherence purification of sputum macrophages was recently published by Bolling et al. [34].

\section{Alveolar macrophage isolation and cell culture}

AM were isolated by repeated flushing of lung resection tissue with PBS using a 19G needle. The collected flush was pelleted by centrifugation $300 g, 5 \mathrm{~min}$. AM pellets were resuspended in Xvivo10 (Lonza \#BE04-743Q) supplemented with $2 \mathrm{mM}$ L-glutamine, $1 \times$ penicillin-streptomycin, $1.25 \mu \mathrm{g} / \mathrm{ml}$ Amphotericin B (all from Gibco, Life technologies) and seeded at a density of $1 \times 10^{6}$ total cells $/ \mathrm{ml}$ in tissue culture treated $25 \mathrm{~cm}^{2}$ flasks (Nunc \#156367, Thermo Scientific). The macrophage fraction was purified by attachment to cell culture plastics for $1 \mathrm{~h}$, followed by three repeated washes with $5 \mathrm{ml}$ Xvivo 10 media. Cultures were rested, or treated with $50 \mathrm{nM}$ Dexamethasone or DMSO, overnight before stimulation with $100 \mathrm{ng} / \mathrm{ml}$ LPS for $2 \mathrm{~h}$ (RNA isolation), $6 \mathrm{~h}$ (measurement of soluble TNF $\alpha$ in media) or $24 \mathrm{~h}$ (conditioned media) at $37{ }^{\circ} \mathrm{C}$ and $5 \% \mathrm{CO}_{2}$. Cell viability prior to seeding were $92 \%$ (90-96), median (range). The purity of the macrophage culture after purification by attachment was monitored by differential staining during the setup of the method $(>95 \%, n=3)$. During the study, the purity of the washed cultures was monitored by visual inspection of cell morphology.

\section{RNA isolation and quantitative RT-PCR}

Total RNA was extracted using RNeasy micro kit (\#74034, Qiagen) and reverse transcription was performed using the ABI high capacity cDNA kit (\#4368813, Life Technologies) according to the manufacturer's instructions. RT-qPCR was carried out using TaqMan gene expression assays (TNF Hs00174128_m1, CCL3 Hs00234142_ $\mathrm{m} 1, I L 1 B$ Hs01555410_m1, GUSB Hs00939627_m1 and POLR2A Hs00172187_m1) on the ABI Quantstudio 7 Flex Real-Time PCR System. Data are normalized to reference genes (GUSB and POLR2A) and presented as fold change $(\mathrm{dCT})$ or as $\log 2$ mean fold change relative to basal conditions (ddCT).

\section{Detection of soluble TNFa}

The Meso Scale Discovery electrochemiluminescence assay (MSD, Gaithersburg) was used to measure absolute levels of TNF $\alpha$ in cell free supernatants from macrophage cultures according to the manufacturer's protocol.

\section{Alveolar macrophage - human bronchial epithelial cell cross-talk assay}

Cell numbers isolated from clinical sputum samples were too low $\left(\sim 0.2-2 \times 10^{6}\right.$ cells/subject $)$ to generate sufficient amounts of conditioned media for the macrophage-epithelial cross-talk assay. For this reason, cell-free conditioned media from alveolar macrophages, which can be isolated in vast numbers from lung resections, were used to study macrophage-HBEC cross-talk in this mechanistic in vitro study.

To generate pseudo-stratified air-liquid-interface (ALI) epithelial cell cultures [35], normal human bronchial epithelial cells (HBECs) (donor \#0000448571 and \#0000485960, Lonza) at passage 2, were seeded at $6.3 \times 10^{4}$ cells $/ \mathrm{cm}^{2}$ on $6.5 \mathrm{~mm}$ polyester insert Transwell plates (\#3478 with \#3395, Corning). The cells were submerged in complete PneumaCult-Ex Plus media (\#05040, STEMCELL Technologies) until air-lift at day 4 after seeding. The cells were then grown in ALI culture in complete PneumaCult-ALI media (\#05001, STEMCELL Technologies) with media renewal every $2-3$ days. After the initiation of mucus production, at approximately day 14 after air-lift, apical mucus was washed off every 2-3 days by incubating the apical cell surfaces with complete media for $2-3 \mathrm{~h}$ at $37^{\circ} \mathrm{C} 5 \% \mathrm{CO}_{2}$ before restoration of ALI. At day 21, the sufficiently differentiated cultures were washed, and the basolateral media was replaced by fresh ALI-media, 1:1 ALI-media +LPS-supplemented (100 ng/ml) Xvivo10 media, 1:1 ALI-media + LPS activated macrophage-conditioned Xvivo10 media with or without the addition of $1 \mu \mathrm{g} / \mathrm{ml}$ neutralizing anti-TNF $\alpha$ monoclonal antibody (clone cA2, \#RAB00046, Abnova) or by $50 \mathrm{ng} / \mathrm{ml}$ huTNFa (\#210-TA/CF, R\&D Systems) in ALI-media with or without $1 \mathrm{ug} / \mathrm{ml}$ neutralizing antiTNF $\alpha$ monoclonal antibody. Triplicate wells/treatment were stimulated for $48 \mathrm{~h}$ at $37^{\circ} \mathrm{C}, 5 \% \mathrm{CO}_{2}$. The apical cell surfaces were then washed with $100 \mu \mathrm{l}$ PBS $\left(\mathrm{Ca}^{2+}\right.$ and $\mathrm{Mg}^{2+}$ free) for $1 \mathrm{~h}$ at $37^{\circ} \mathrm{C}$. The cells were fixed with 4\% formaldehyde (\#9713100, VWR) for $20 \mathrm{~min}$ at RT, washed three times with PBS and stored submerged in $\mathrm{PBS}$ at $+4{ }^{\circ} \mathrm{C}$ for immunocytochemistry.

\section{Immuno-cytochemistry of whole-mount ALI cultures}

The fixed cells were washed once with PBS and permeabilized with PBS $+0.25 \%$ TritonX-100 (\#1001541166, Sigma-Aldrich) for $20 \mathrm{~min}$. The inserts were washed three times and blocked with PBS+1\% BSA (\#1002119388, Sigma Aldrich) $+2 \%$ goat serum (\#S-1000, Vector labs) at $+4{ }^{\circ} \mathrm{C}$ overnight, then incubated with $\mathrm{PBS}+1 \%$ $\mathrm{BSA}+2 \%$ goat serum $+5 \mu \mathrm{g} / \mathrm{ml}$ anti-MUC5B (\#ab77995, 
Abcam) for $2 \mathrm{~h}$. The cells were washed four times for 5 min and stained with PBS + goat anti-mouse IgG Alexa Fluor568 (\#A21124, Invitrogen, 1:400) + Alexa Fluor 488 Phalloidin (\#A12379, Invitrogen, 1:50) for $1 \mathrm{~h}$, protected from light. The inserts were washed two times for $5 \mathrm{~min}$ and counterstained with PBS + Hoechst 33342 (\#62249, Thermo Fisher Scientific, $1 \mu \mathrm{g} / \mathrm{ml}$ ) for $10 \mathrm{~min}$. After four 5 -min washes, the membranes were removed from the culture inserts and mounted using Vectashield mounting media (\#H-1000, Vector labs). Three representative images/membrane were captured using an LSM 880 Airyscan microscope (Zeiss) and the percentage of MUC5B/ total image area was quantified using the Visiopharm Integrator System (Visiopharm A/S). All immunocytochemistry data are presented as mean of three independent experiments using cell-free conditioned media from three different AM donors and triplicate technical replicates.

\section{Proteome profiler analysis of ALI cultures}

ALI-HBEC, stimulated basolaterally for $30 \mathrm{~min}$, with 1:1 ALI-media + Xvivo10 media with $100 \mathrm{ng} / \mathrm{ml} \mathrm{LPS} \mathrm{or} 1: 1$ ALI-media + LPS-activated macrophage-conditioned media at day 21 after air-lift, were processed and analyzed according to the manufacturer's instructions in the proteome profiler human phospho-kinase array kit (ARY003B, R\&D Systems). Mean pixel densities were calculated from scanned X-ray films using Image Studio 4.0 (LI-COR Biosciences).

\section{Statistical analysis}

Experimental data are presented as individual experiments with mean \pm standard deviation or range when indicated. Clinical data are presented as median with (range). For single comparisons, one-sided Welch t-tests were used and for multiple comparisons, one-way ANOVA with Šidák's correction for multiple comparisons were performed. QQ plots were used to check for normality assumption and a sandwich estimator was used to obtain a consistent estimate of the variance of the residuals due to heteroscedasticity. Analysis was performed in R [36] and data was plotted using GraphPad Prism 8. Significant $\mathrm{p}$-values are represented as * $\mathrm{p}<0.05$; ** $\mathrm{p}<0.01 ;{ }^{* * *} \mathrm{p}<0.001 ; \mathrm{ns}=$ not significant.

\section{Results}

\section{Subject characteristics}

Clinical characteristics of the chronic bronchitis COPD cohort at time of inclusion are presented in Tables 1,2 and 3. All patients were current or former tobacco smokers with smoking pack years history of 41.8 (8-75), median (range), and had a diagnosis of chronic bronchitis and COPD GOLD stage I, II or III.

Median of COPD assessment test (CAT) was 22 (9-35) out of a maximum value of 40 and median of the short CB questionnaire $34.3(27-42)$ out of a maximum value of 45 confirming active disease of $\mathrm{CB}$ in this cohort.

Blood test showed that median of CRP 2.55 (1.017) $\mathrm{mmol} / \mathrm{l}$ [reference value $<5 \mathrm{mmol} / \mathrm{l}]$, leukocytes $7.9(6.8-10)[3.5-8.8] * 10^{9} / 1$ and neutrophils $4.9(2.8-$ $6.6) * 10^{9} / 1$ [1.8-7.5] were all in the upper part of reference values. On the contrary, median of eosinophils 0.2 $(0.05-0.6)[0.04-0.4] * 10^{9} / 1$, was in the lower part of reference values.

Further, as expected in this patient population, sputum cell counts showed an increase in sputum neutrophils 77.6 (63.7-94.4)\% (Table 3) compared to 69\% that has been reported for age-matched healthy volunteers [37]. Taken together, these data indicate that the patients tested here correlate well with a neutrophilic COPD phenotype.

\section{Human bronchial epithelial cells grown in ALI culture are inert to direct LPS stimulus but respond} when the inflammatory signal is relayed via macrophages The effect of LPS stimulation on primary human bronchial epithelial cells (HBEC) grown as ALI cultures was investigated by measuring the production of the major mucus component, MUC5B (Fig. 1A). Direct basal stimulation of HBEC ALI cultures by LPS (LPS only) caused no increase in MUC5B expression ( $p=0.97)$. In contrast, the conditioned media from LPS stimulated AMs (AM LPS) evoked a significant increase in MUC5B expression in the ALI cultures $(p=0.017)$. In line with this finding, neither conditioned media from unstimulated AM (AM no LPS), nor media alone (Vehicle) had any effect on epithelial MUC5B expression. Taken together, these data clearly show that the inflammatory signal is relayed through the alveolar macrophages and mediated by a soluble factor, which was later investigated (see below).

\section{Conditioned media from LPS-activated alveolar macrophages phosphorylate CREB/AP1 transcription factors in human bronchial epithelial cells}

To unravel the signaling pathways leading to increased MUC5B expression after addition of conditioned media from LPS stimulated alveolar macrophages, we performed a kinase phosphorylation analysis in ALI cultured HBECs including 43 different human kinases (Proteome profiler array). After $30 \mathrm{~min}$ of stimulation by conditioned media from activated alveolar macrophages from two different AM donors (d1 and $\mathrm{d} 2$ ), 

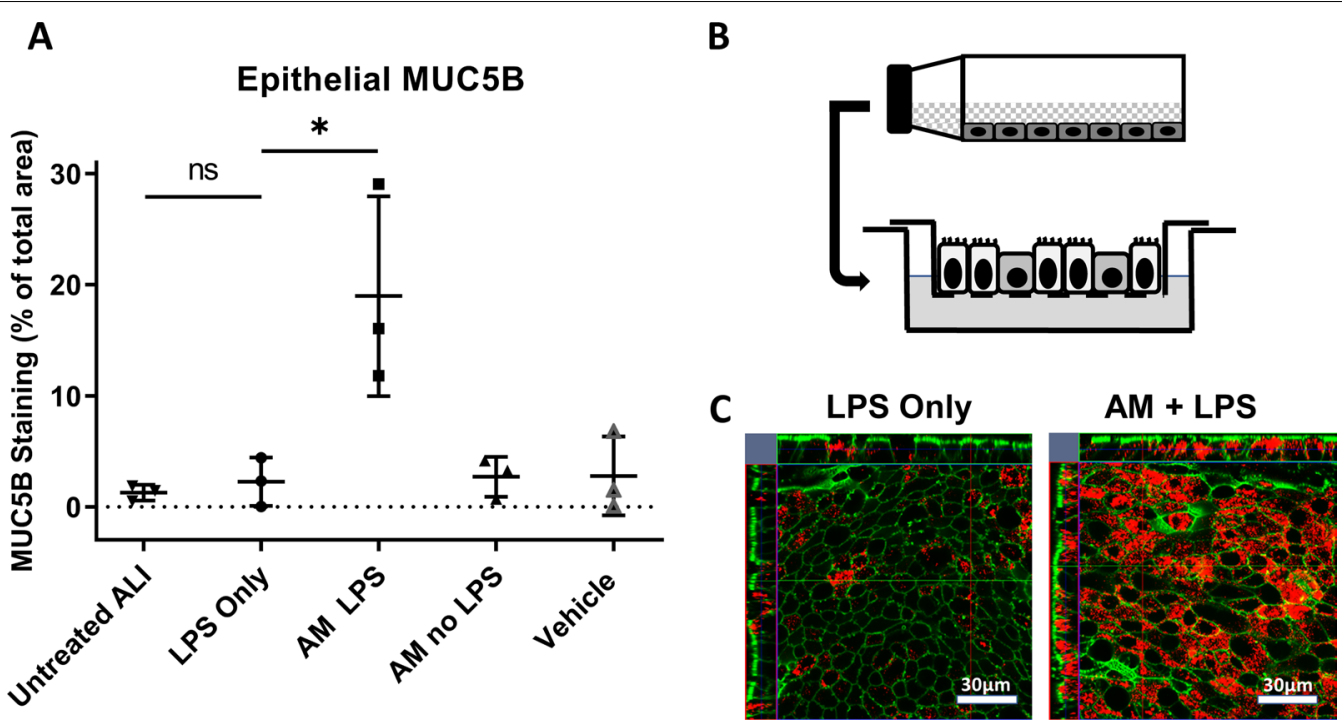

Fig. 1 Macrophages relay inflammatory signals to epithelial cells through a soluble factor. Intracellular MUC5B staining of human bronchial epithelial cells (HBEC), grown in ALI culture. A Five different conditions were investigated in HBECs: Untreated ALI, media with $100 \mathrm{ng} / \mathrm{ml}$ LPS, conditioned media from LPS activated AM from three different donors, conditioned media from same AM donors without LPS or by addition of 50\% Xvivo-10 macrophage media alone (Vehicle control). Data are presented as mean \pm standard deviation from three independent experiments using conditioned media from three different AM donors and triplicate technical replicates. B Schematic drawing depicting basolateral transfer of conditioned macrophage media to ALI cultures in transwell plates. C Representative confocal scans of MUC5B in whole-mount ALI cultures stimulated with LPS only or conditioned media from LPS activated macrophages (Green = Phalloidin, Red = MUC5B)

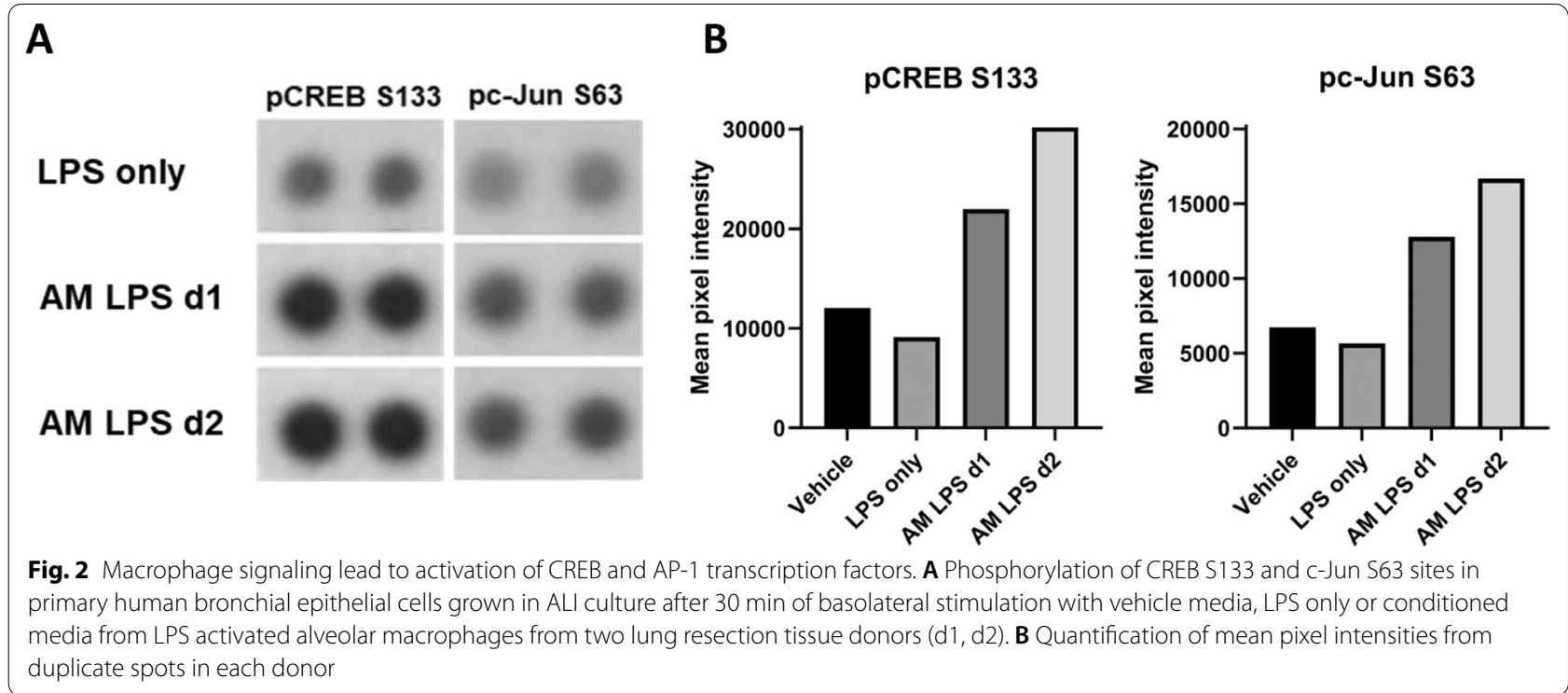

the kinases CREB and c-Jun showed increased phosphorylation on S133 and S63, respectively, compared to basic stimulation with LPS alone (Fig. 2). These data suggest that macrophage signaling lead to activation of
CREB and AP-1 transcription factor complexes which are both considered key players regulating mucin genes in human epithelial cells [38, 39]. 


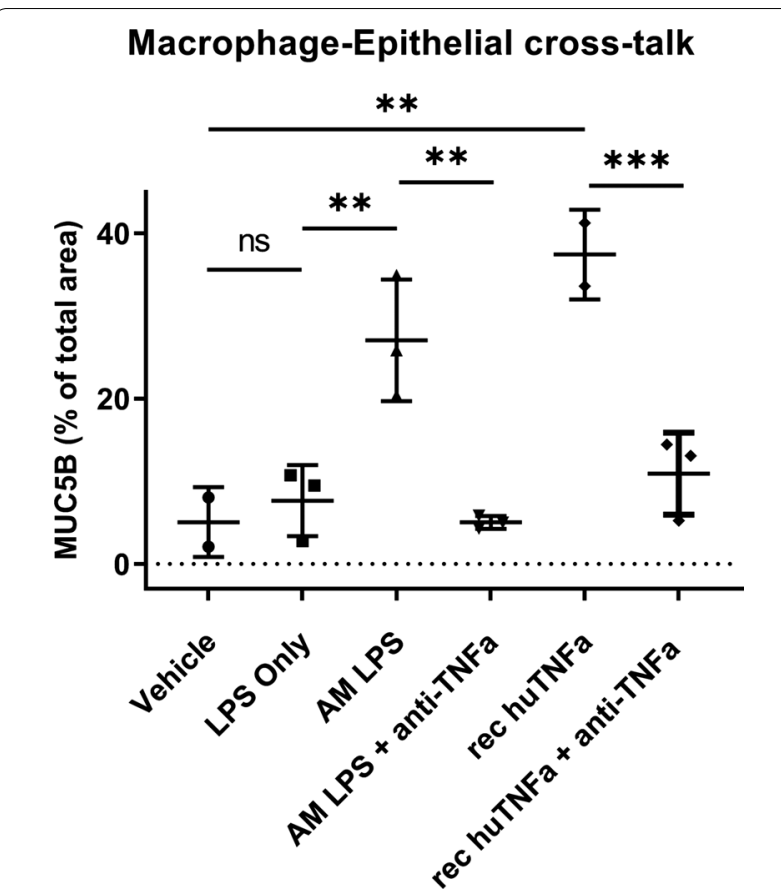

Fig. 3 TNFa released from macrophages in response to bacterial LPS, plays a key role in driving mucus production in bronchial epithelial cells. Intracellular MUC5B staining in whole-mounts of human bronchial epithelial cells, grown as ALI cultures. Conditions include: Unstimulated (Vehicle), direct stimulation with LPS, stimulation with conditioned media from LPS activated macrophages w/wo addition of a TNFa-neutralizing antibody or direct stimulation with $50 \mathrm{ng}$ recombinant TNFa w/wo addition of a TNFa-neutralizing antibody. Data are presented as mean \pm standard deviation from three independent experiments using conditioned media from three different AM donors and triplicate technical replicates

\section{Macrophage-derived TNFa is a key driver of MUC5B} in bronchial epithelial cells

The major LPS inducible macrophage-derived mediator TNF $\alpha$ has been shown to activate CREB and AP-1 transcription factor complexes through TNFR1 (via p38MAPK/MSK1) and TNFR2 (via JNK) [40, 41]. We next investigated the possible involvement of TNF $\alpha$ in mediating the downstream effects on MUC5B expression in epithelial cells grown in ALI culture using neutralizing antibodies and recombinant human TNF $\alpha$ (Fig. 3). Direct stimulation of the epithelial cells by recombinant human TNF $\alpha$ (rec huTNFa) resulted in a strong upregulation of MUC5B ( $p=0.0003)$. Again, conditioned media from activated macrophages (AM LPS) resulted in a significant upregulation of epithelial MUC5B $(p=0.0035)$. Interestingly, the addition of neutralizing TNF $\alpha$ antibodies to the conditioned media from LPS stimulated alveolar macrophages (AM LPS + anti-TNFa) completely abolished the effect of macrophage-conditioned media on epithelial MUC5B expression $(\mathrm{p}=0.0014)$. Also, addition of neutralizing TNF $\alpha$ antibodies to the recombinant TNF $\alpha$ media (rec huTNFa + anti-TNFa) reduced the expression of MUC5B to basal levels $(p=0.0008)$. Taken together, these mechanistic data show that TNF $\alpha$ released from macrophages in response to bacterial LPS, plays a key role in mucus production in bronchial epithelial cells.

\section{Macrophages from chronic bronchitis sputum are chronically activated}

Expression of the pro-inflammatory genes encoding $T N F, I L 1 B$ and CCL3 by $2 \mathrm{~h}$ LPS stimulation was studied in ex vivo isolated sputum macrophages from $\mathrm{CB}$

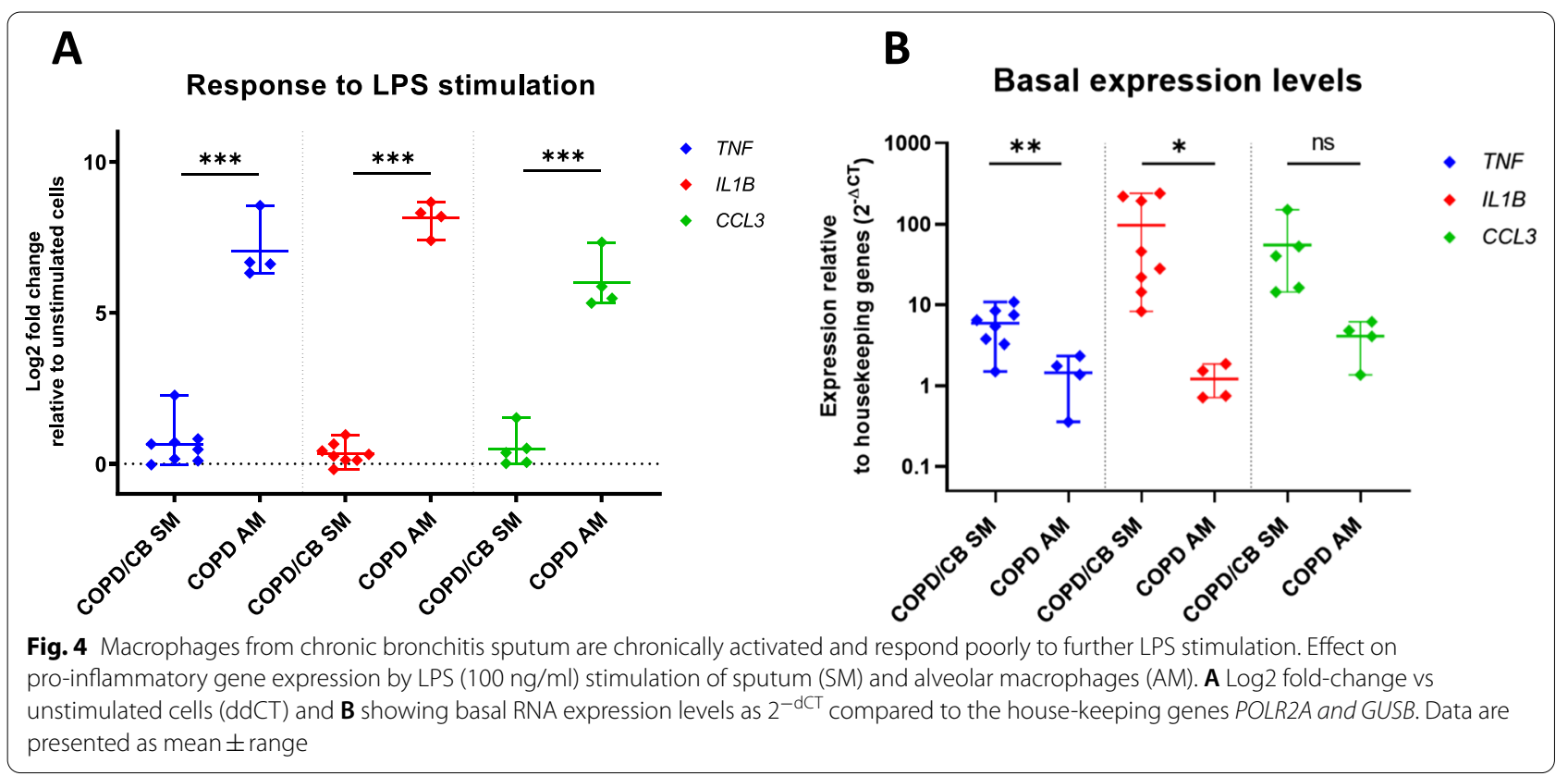


patients and compared to the effect seen in alveolar macrophages isolated from lung resections. After LPS stimulation, no significant fold-change (ddCT) induction of RNA levels of these genes were seen in sputum macrophages, showing that these cells are unresponsive to LPS stimulation (Fig. 4A). However, by comparing levels of basal TNF, IL1B and CCL3 RNA expression normalized against the POLR2A and GUSB housekeeping genes $(\mathrm{dCT})$, we showed that TNFa $(\mathrm{p}=0.0041)$ and IL1B $(\mathrm{p}=0.033)$ transcripts were already partially increased in unstimulated sputum macrophages showing that this cell population is chronically activated in the lung environment (Fig. 4B). In contrast to the effects seen in sputum macrophages, alveolar macrophages isolated from lung resections show little or no basal activation but are strongly activated in vitro by LPS stimulation $(\mathrm{p}=0.00008 ; \mathrm{p}=0.00001 ; \mathrm{p}=0.00007$ for TNF, IL1B and CCL3 respectively) (Fig. 4A).

\section{Sputum macrophages from COPD chronic bronchitis patients are steroid resistant}

Given the importance of TNF $\alpha$ as mediator in the mechanistic macrophage-epithelial cross-talk assay and the chronic TNF expression observed in the clinically sampled sputum macrophages, the effect of the corticosteroid dexamethasone was investigated by measuring the amount of TNF $\alpha$ protein released into the media of ex vivo cultured sputum and alveolar macrophages. When exposed to dexamethasone $(50 \mathrm{nM})$ prior to LPS stimulation, only partial reduction in TNF $\alpha$ levels was seen in sputum macrophages ( $24 \%$ vs vehicle, $n=5)$ isolated from chronic bronchitis COPD patients (COPD/CB $\mathrm{SM} \mathrm{DEX})$, compared to a significantly larger response in both COPD alveolar macrophages ( $75 \%$ vs vehicle, $n=4)$, (COPD AM DEX) as well as non-COPD alveolar macrophages (72\% vs vehicle, $n=4)$, (non-COPD AM DEX) isolated from lung resections (Fig. 5A). Taken together, these data show that, in contrast to alveolar macrophages from either COPD or non-COPD donors, sputum macrophages from COPD chronic bronchitis patients are steroid resistant $(\mathrm{p}=0.0008$ and 0.0011 , respectively). Further, comparison of the sputum neutrophil differential counts and steroid responsiveness (\% inhibition of TNFa) revealed a potential direct correlation between sputum neutrophils and sputum macrophage steroid resistance $\left(\mathrm{R}^{2}=0.936, \mathrm{p}=0.0071\right)$ (Fig. $\left.5 \mathrm{~B}\right)$.

\section{Discussion}

In the current study, we have evaluated the inflammatory state of purified sputum macrophages from COPD chronic bronchitis patients and for the first time investigated the response to pharmacological inhibition by steroids in this isolated cell fraction. We found an apparent disconnect in both the inflammatory state and in the
A

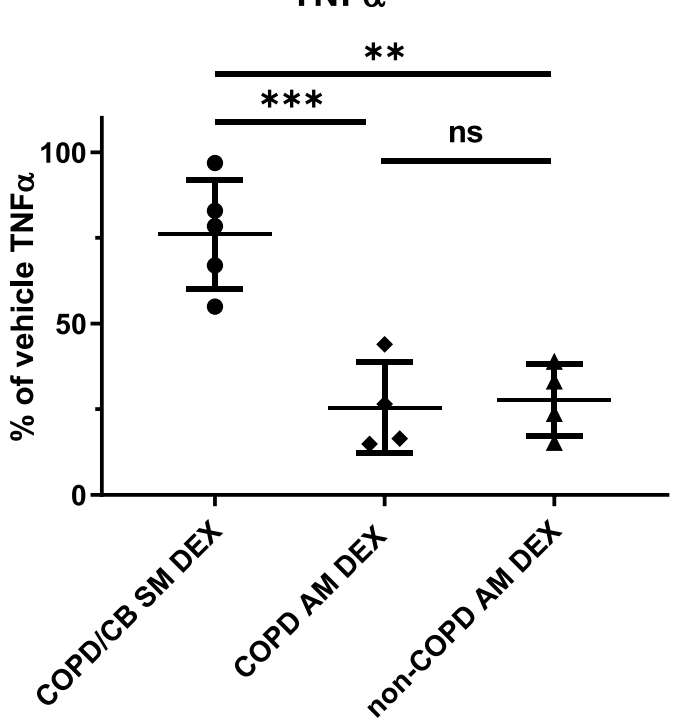

B

Sputum macrophage correlation plot

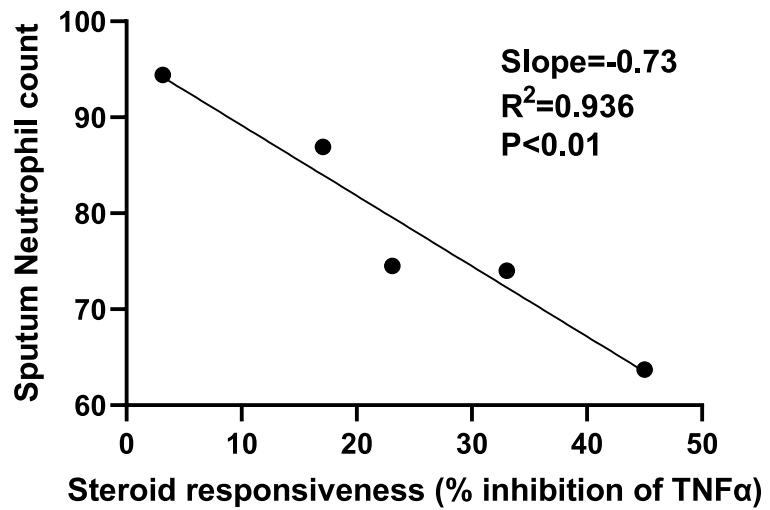

Fig. 5 Sputum macrophages from COPD chronic bronchitis patients are steroid resistant. A Effect of $50 \mathrm{nM}$ dexamethasone (DEX) on TNFa protein levels in media from LPS stimulated CB sputum macrophages (COPD/CB SM) $(n=5)$ and alveolar macrophages (AM) from COPD or non-COPD patients $(n=4)$. Cells were pre-treated with compound or DMSO vehicle for $22 \mathrm{~h}$ and subsequently stimulated with LPS (100 $\mathrm{ng} / \mathrm{ml})$ for $6 \mathrm{~h}$. Data are presented as mean \pm standard deviation. $\mathbf{B}$ Linear regression correlation plot comparing sputum neutrophil differential counts (\%) and sputum macrophage steroid responsiveness (\% inhibition of TNFa at $50 \mathrm{nM}$ dexamethasone) 
response to glucocorticoids between macrophages isolated from sputum or alveolar macrophages isolated from lung resections, suggesting chronic activation and steroid resistance in sputum-derived macrophages. Further, using a primary human macrophage and bronchial-epithelial cell co-culture system we show that LPS signaling at the epithelial surface is relayed through macrophages and that macrophage-derived TNF $\alpha$ is a key mediator activating CREB/AP1-driven MUC5B expression in lung epithelial cells.

Chronic bronchitis is associated with persistent airway inflammation in the lining of bronchial tubes and an increase in mucus production leading to mucus hyperconcentration and bacterial colonization driving further mucus production. The hyper-concentration of mucus positively correlates with exacerbation frequencies and has been proposed as a disease driver in chronic bronchitis with MUC5B remaining the predominant mucin at all levels of disease severity [13, 42]. Epithelial cells are relatively inert to LPS stimulation and previous reports have shown that only very high LPS concentration over a long period can drive mucus expression in experimental systems of lung epithelium [43]. On the other hand, macrophages isolated from lung resections, readily respond to even low amounts of LPS. Thus, macrophages seem to function as sentinels of the lung by sensing the presence of pathogens and respond by cytokine/chemokine signaling. Cross-talk between macrophages and lung epithelium may be instrumental in providing optimal host protection against infections and noxious agents as the mucus layer provides an efficient barrier to trap and remove bacteria by the mucociliary escalator system. However, in disease this system is perturbated, resulting in chronic stimulation and activation of signals driving mucus hyper-production and ultimately hyper-concentration, thus impairing mucociliary clearance and leaving the cough reflex as the essential remaining functional clearance mechanism. Clinically, this is presented as the productive sputum and cough defining a chronic bronchitis patient [4].

We have set up a novel, fully primary human cell system to study macrophage-epithelial cross-talk driving MUC5B protein expression. For practical reasons, alveolar macrophages were used to perform these mechanistic studies, investigating how signals released from macrophages can drive mucus expression in epithelial cells. Firstly, AM can be isolated in large quantities by flushing of resection tissue. Secondly, they are quiescent cells and release very low or undetectable levels of TNF $\alpha$ when cultured in vitro without stimuli and they are also highly responsive to LPS stimulation, which was confirmed by us at the RNA level before and after LPS stimulation (Fig. 4). Using this system, we clearly show that bacterial
LPS can activate the alveolar macrophage, which in turn signals through the release of TNF $\alpha$ to the epithelial cells. This signal, in turn activates MUC5B protein production in the epithelial columnar goblet cells that secrete gelforming mucins. In this respect, the ALI culture of pseudostratified human bronchial epithelia represents a good model of COPD/CB airway epithelium exhibiting goblet cell meta/hyperplasia [8]. Further, using a phosphoproteome profiler approach we show that macrophage signaling activates CREB S133 and c-Jun S63 in epithelial cells supporting previous reports of CREB and AP-1 regulation as key transcription factors regulating mucin genes in human epithelial cells [38, 39]. TNF $\alpha$ has the potential to activate both these transcription factors in lung epithelial cells, similar to what has previously been shown in endothelial cells where TNF $\alpha$ activates CREB and c-JUN through TNFR1 (via p38MAPK/MSK1) and TNFR2 (via JNK), respectively [40, 41]. Interestingly, both IL1 $\beta$ and TNF $\alpha$ can activate CREB S133 phosphorylation in human nasal epithelial cells [44] and the MUC5B promoter harbors numerous transcription factor sites for CREB [45]. Other stimuli such as reactive oxygen species (ROS) emanating from cigarette smoke exposure have been shown to directly activate the MUC5B defense mechanism in epithelial airway cells [12]. While both activation of macrophages and direct activation of epithelial cells by ROS are indeed possible drivers of disease during the development of chronic bronchitis, the chronic activation of SM reported here, may represent a mechanism behind persistent mucus secretion perpetuating the disease state even after smoking cessation.

Despite the accessibility of sputum macrophages, ex vivo pharmacological intervention of inflammatory responses in purified populations of these cells has not previously been investigated. However, studies of acute effects on total sputum cells confirm steroid resistance and LPS unresponsiveness which may be a consequence of the unique environment these cells are residing in, both regarding cytokine and chemokine levels, but also considering the ROS and proteases released by the vast number of neutrophils in this niche [46].

Recently, a method describing the isolation and culturing of human sputum macrophages from healthy volunteers was published, with similarities to the method described here [34]. In this paper, the authors showed that even though sputum macrophages exhibited a highly pro-inflammatory signal directly after isolation, the levels were reduced after $20 \mathrm{~h}$ of culturing and that the ex vivo macrophages responded with lower but significant TNF $\alpha$ expression in response to stimulation with LPS. The difference between this report and the lack of LPS responsiveness in our study may be explained by differences in culture conditions, LPS dose $(1 \mu \mathrm{g} / \mathrm{ml}$ compared to the 
$100 \mathrm{ng} / \mathrm{ml}$ used in our study) or by the origin of the macrophages since our study used selected sputum plugs while this report used the entire expectorate as source for sputum macrophage isolation. By comparison to alveolar macrophages from lung resections, we clearly show that there is a large difference in response to LPS between sputum macrophages ( $<$ twofold in our study and $\sim$ threefold in the study by Bolling et al. [34]) and alveolar macrophages ( 100-fold in this study), suggesting that statistically relevant induction and biologically relevant induction of TNFa may differ. Previous investigations in healthy subjects have shown that there is a clear difference, both in functional activation [47] and metabolic activity [48], between sputum and alveolar macrophages and it is likely that the findings described here is a consequence of distinct local microenvironments present in the upper and lower respiratory tract rather than a direct feature of chronic bronchitis. However, in COPD chronic bronchitis patients, the numbers of sputum plugs, neutrophils and macrophages are increased as a consequence of the chronic inflammatory state of their lungs, which may perpetuate disease through the vicious cycle of sputum hyper-production and hyper-concentration. In fact, it was recently shown that mucus plugs and emphysema was independently associated with FEV1 and that the effect sizes on airflow obstruction between these entities were similar [49]. Further, sputum neutrophilia correlated with high mucus plug scores, high COPD Assessment Test (CAT) scores and more frequent annual exacerbations [49], showing the importance of mucus plug abundance in disease progression.

Several investigations have shown high pro-inflammatory cytokine and chemokine levels in sputum supernatants including TNF $\alpha$, IL1 $\beta$ and CCL3 $[2,50]$. While this may appear counter-intuitive to the lack of response to LPS found in this study, it may be explained by a moderate, chronic expression over time. Chronic activation of macrophages makes them less efficient to evoke a strong immediate peak in pro-inflammatory cytokine expression and this may reduce their ability to counteract bacteria entering the lung and could possibly represent a basis for bacterial colonization of the lung, frequently seen in COPD patients.

In this study, we show that purified sputum macrophages from patients with chronic bronchitis and COPD exposed to dexamethasone, show steroid resistance compared to alveolar macrophages isolated from non-COPD and COPD patient lung resections, thus identifying a possible basis for the clinically observed steroid resistance in the COPD/CB patient population.

Contrary to the situation in asthmatic patients, inhaled steroids in COPD have been shown to be much less effective in improving lung function and controlling the underlying chronic inflammation. Only a fraction of COPD patients show a direct clinical response to inhaled corticosteroids and these patients often have increased numbers of eosinophils and show bronchodilator reversibility [51]. However, maintenance steroid treatment is still part of the current clinical practice to reduce exacerbation frequency in COPD/CB. Several mechanisms and mediators are known to be implicated in the development of steroid resistance. The neutrophilic inflammation generates local oxidative stress that activates lung epithelial cells and alveolar macrophages, from which proinflammatory cytokines are released. These inflammatory cytokines are potent mediators for steroid resistance by suppressing the glucocorticoid receptor [52]. Further, inflammasome activation and subsequent IL1 $\beta$ expression, known to be present in COPD, has been shown to drive experimental severe, steroid-resistant asthma [53]. In this context, it is interesting to note that the sputum macrophages showing the most pronounced resistance to the effect of dexamethasone were derived from the subject with the highest percentage of neutrophils in sputum plugs (subject 5), while the sputum macrophages from the patient with the least neutrophils and instead the highest eosinophil percentage in sputum plugs (subject 6, possibly a mixed COPD/Asthma phenotype) shows the least steroid resistance of all patients (Fig. 5B). While these data suggest a direct correlation between sputum neutrophil content and steroid resistance, replication of these data in a larger cohort is needed to fully establish this connection. TNF $\alpha$-neutralizing antibodies have shown good effects in multiple auto-immune chronic inflammatory condition including rheumatoid arthritis, Crohn's disease and psoriasis [54]. However, despite multiple clinical trials to evaluate anti-TNF $\alpha$ agents in COPD patients, no clear efficacy could be established warranting use in this disease $[55,56]$. The failure of anti-TNF- $\alpha$ therapy in COPD may have several causes. If, in coming studies, the phenotypes of COPD would be better characterized, one could more specifically identify which patients may benefit from TNF $\alpha$ inhibitors [57]. However, since many, if not all, of the current trials lack target engagement markers confirming the ability of the agent to reach the target TNF $\alpha$ producing cells, it would be of particular interest to study access of anti-TNF $\alpha$ antibodies or antibody-like proteins into sputum plugs where we suggest the main fraction of steroid resistant cells reside in COPD.

The main limitation of the current study is the small number of COPD/CB patients studied, the restricted numbers of sputum macrophages that could be isolated from each patient and the lack of a control group of either non-bronchitis COPD patients or healthy subjects that would have enabled a disease vs 
non-disease comparison. However, given the large differences in baseline proinflammatory gene expression and response to LPS and corticosteroids observed between SM and AM, this study was still powered to detect significant phenotypic hallmarks of CB sputum macrophages, but further studies with larger sample sizes are needed to more accurately quantify the differences described here. Similarly, restricted numbers of isolated SM from induced sputum samples prevented dose-response evaluation of dexamethasone in these cells. To circumvent this limitation, a dose-response investigation in AM was performed (data not shown), enabling us to select a precise dose to detect differences between SM and AM. Also, comparison of SM which are considered a heterogenous population regarding morphology, maturation and activation state to the more homogenous AM popolation may complicate statistical comparison due to differences in the distribution of data. However, statistical methods monitoring normality assumption and variance estimates were used to assure proper statistical comparison between these groups.

In conclusion, our data pinpoint a critical role for sputum macrophages in chronic bronchitis by perpetuating macrophage-epithelial signaling that can drive aberrant mucin expression in bronchial epithelial cells. Novel strategies targeting the steroid-resistant, chronically activated phenotype of sputum plug macrophages are warranted to drive resolution of chronic inflammation in the lungs of patients suffering from COPD with chronic bronchitis.

\section{Abbreviations}

COPD: Chronic obstructive pulmonary disease; CB: Chronic bronchitis; AM: Alveolar macrophage; SM: Sputum macrophage; BAL: Bronchoalveolar lavage; LPS: Lipopolysaccharide; TNF-a: Tumor necrosis factor-a; IL: Interleukin; CCL: Chemokine (C-C motif) ligand; CXCR: CXC chemokine receptors; CCR: C-C chemokine receptor; PDE: Phosphodiesterase; FEV1: Forced expiratory volume in $1 \mathrm{~s}$; CAT: COPD assessment test; CRP: C-reactive protein; ALI: Air-liquidinterface; HBEC: Human bronchial epithelial cell.

\section{Supplementary Information}

The online version contains supplementary material available at https://doi. org/10.1186/s12931-021-01762-4.

Additional file 1: Table S1. CB questionnaire.

Additional file 2: Table S2. Subject characteristics of lung resection tissue donors.

\section{Acknowledgements}

The authors thank the study participants, research staff and clinical staff for making this research possible. We would especially like to acknowledge research nurses Ann-Sofie Rönnholm and Mathias Hufnagl at the COPD Centre at Sahlgrenska University Hospital for their excellent assistance in conducting this study.

\section{Authors' contributions}

Conceived and designed the current manuscript study: KA, AA, ZJ, MG. Developed study protocols: KA, KÖ, AA, ZJ, MG. Collected data: KA, KÖ, ZJ, MG. Analyzed and interpreted data: KA, KÖ, AA, ZJ, EM, LV, MG. Prepared and edited the manuscript: KA, KÖ, AA, ZJ, EM, LV, MG. All authors read and approved the final manuscript.

\section{Funding}

The study was funded by AstraZeneca and employees of AstraZeneca participated in the study design, data collection, data analysis, data interpretation, and the writing of the manuscript. AstraZeneca reviewed the publication, without influencing the opinions of the authors, to ensure medical and scientific accuracy and the protection of intellectual property. The authors had access to all data in the study, and had the final responsibility for the decision to submit the manuscript for publication.

\section{Availability of data and materials}

All data used in this manuscript are provided within the Main manuscript or in the Additional data files.

\section{Declarations}

\section{Ethics approval and consent to participate}

This study was conducted in accordance with the amended Declaration of Helsinki and approved by the ethics committee at the University of Gothenburg, Sweden, Approval number 501-17, T 820-17 and 1026-15. Written informed consent was obtained from all patients.

\section{Consent for publication}

Not applicable.

\section{Competing interests}

KÖ, ZJ, EM and MG are AstraZeneca employees and hold stocks/stock options in AstraZeneca, which supported the study.

\section{Author details}

${ }^{1}$ COPD Center, Dept of Respiratory Medicine and Allergology, Sahlgrenska University Hospital, Gothenburg, Sweden. ${ }^{2}$ COPD Center, Dept of Internal Medicine and Clinical Nutrition, Institute of Medicine, Sahlgrenska Academy, University of Gothenburg, Gothenburg, Sweden. ${ }^{3}$ Department of Bioscience COPD/IPF, Research and Early Development, Respiratory and Immunology (R\&l), BioPharmaceuticals R\&D, AstraZeneca, Pepparedsleden 1, 43153 Gothenburg, Sweden. ${ }^{4}$ Data Sciences and Quantitative Biology, Discovery Sciences, BioPharmaceuticals R\&D, AstraZeneca, Gothenburg, Sweden. ${ }^{5}$ Translational Science and Experimental Medicine, Research and Early Development, Respiratory and Immunology (R\&l), BioPharmaceuticals R\&D, AstraZeneca, Gothenburg, Sweden.

Received: 4 December 2020 Accepted: 27 May 2021

Published online: 07 June 2021

\section{References}

1. Singh D, Kolsum U, Brightling CE, Locantore N, Agusti A, Tal-Singer R, et al. Eosinophilic inflammation in COPD: prevalence and clinical characteristics. Eur Respir J. 2014:44(6):1697-700.

2. Ghebre MA, Bafadhel M, Desai D, Cohen SE, Newbold P, Rapley L, et al. Biological clustering supports both "Dutch" and "British" hypotheses of asthma and chronic obstructive pulmonary disease. J Allergy Clin Immunol. 2015;135(1):63-72.

3. Corhay JL, Vincken W, Schlesser M, Bossuyt P, Imschoot J. Chronic bronchitis in COPD patients is associated with increased risk of exacerbations: a cross-sectional multicentre study. Int J Clin Pract. 2013;67(12):1294-301.

4. Medical Research Council. Definition and classification of chronic bronchitis for clinical and epidemiological purposes. A report to the Medical Research Council by their Committee on the Aetiology of Chronic Bronchitis. Lancet. 1965;1(7389):775-9.

5. Saetta M, Turato G, Baraldo S, Zanin A, Braccioni F, Mapp CE, et al. Goblet cell hyperplasia and epithelial inflammation in peripheral airways of 
smokers with both symptoms of chronic bronchitis and chronic airflow limitation. Am J Respir Crit Care Med. 2000;161 (3 Pt 1):1016-21.

6. Caramori G, Casolari P, Barczyk A, Durham AL, Di Stefano A, Adcock I. COPD immunopathology. Semin Immunopathol. 2016;38(4):497-515.

7. Lahousse L, Seys LM, Joos GF, Franco OH, Stricker BH, Brusselle GG. Epidemiology and impact of chronic bronchitis in chronic obstructive pulmonary disease. Eur Respir J. 2017;50(2):1602470.

8. Kesimer M, Kirkham S, Pickles RJ, Henderson AG, Alexis NE, Demaria G, et al. Tracheobronchial air-liquid interface cell culture: a model for innate mucosal defense of the upper airways? Am J Physiol Lung Cell Mol Physiol. 2009;296(1):L92-100.

9. Ma J, Rubin BK, Voynow JA. Mucins, mucus, and goblet cells. Chest. 2018;154(1):169-76.

10. Ridley C, Thornton DJ. Mucins: the frontline defence of the lung. Biochem Soc Trans. 2018:46(5):1099-106.

11. Hovenberg HW, Davies JR, Carlstedt I. Different mucins are produced by the surface epithelium and the submucosa in human trachea: identification of MUC5AC as a major mucin from the goblet cells. Biochem J. 1996;318(Pt 1):319-24.

12. Casalino-Matsuda SM, Monzon ME, Day AJ, Forteza RM. Hyaluronan fragments/CD44 mediate oxidative stress-induced MUC5B up-regulation in airway epithelium. Am J Respir Cell Mol Biol. 2009;40(3):277-85.

13. Kesimer M, Ford AA, Ceppe A, Radicioni G, Cao R, Davis CW, et al. Airway mucin concentration as a marker of chronic bronchitis. N Engl J Med. 2017;377(10):911-22.

14. Kirkham S, Kolsum U, Rousseau K, Singh D, Vestbo J, Thornton DJ. MUC5B is the major mucin in the gel phase of sputum in chronic obstructive pulmonary disease. Am J Respir Crit Care Med. 2008;178(10):1033-9.

15. Hogg JC. Pathophysiology of airflow limitation in chronic obstructive pulmonary disease. Lancet. 2004;364(9435):709-21.

16. Barnes PJ. Inflammatory mechanisms in patients with chronic obstructive pulmonary disease. J Allergy Clin Immunol. 2016;138(1):16-27.

17. Capelli A, Di Stefano A, Gnemmi I, Balbo P, Cerutti CG, Balbi B, et al. Increased MCP-1 and MIP-1 beta in bronchoalveolar lavage fluid of chronic bronchitics. Eur Respir J. 1999:14(1):160-5.

18. Lofdahl JM, Wahlstrom J, Skold CM. Different inflammatory cell pattern and macrophage phenotype in chronic obstructive pulmonary disease patients, smokers and non-smokers. Clin Exp Immunol. 2006;145(3):428-37.

19. Berenson CS, Wrona CT, Grove LJ, Maloney J, Garlipp MA, Wallace PK, et al. Impaired alveolar macrophage response to Haemophilus antigens in chronic obstructive lung disease. Am J Respir Crit Care Med. 2006;174(1):31-40.

20. Brown GP, Iwamoto GK, Monick MM, Hunninghake GW. Cigarette smoking decreases interleukin 1 release by human alveolar macrophages. Am J Physiol. 1989:256(2 Pt 1):C260-4.

21. Ohta T, Yamashita N, Maruyama M, Sugiyama E, Kobayashi M. Cigarette smoking decreases interleukin-8 secretion by human alveolar macrophages. Respir Med. 1998;92(7):922-7.

22. Soliman DM, Twigg HL 3rd. Cigarette smoking decreases bioactive interleukin-6 secretion by alveolar macrophages. Am J Physiol. 1992;263(4 Pt 1):L471-8.

23. Donnelly LE, Barnes PJ. Chemokine receptors as therapeutic targets in chronic obstructive pulmonary disease. Trends Pharmacol Sci. 2006:27(10):546-53.

24. Garrood T, Lee L, Pitzalis C. Molecular mechanisms of cell recruitment to inflammatory sites: general and tissue-specific pathways. Rheumatology (Oxford). 2006;45(3):250-60

25. Kolaczkowska E, Kubes P. Neutrophil recruitment and function in health and inflammation. Nat Rev Immunol. 2013;13(3):159-75.

26. Miyamoto K, Matsukawa A, Ohkawara S, Takagi K, Yoshinaga M. IL-8 is involved in homologous TNF alpha-, but not in IL-1 beta-induced neutrophil infiltration in rabbits. Inflamm Res. 1997;46(11):472-7.

27. Montecucco F, Steffens S, Burger F, Da Costa A, Bianchi G, Bertolotto M, et al. Tumor necrosis factor-alpha (TNF-alpha) induces integrin CD1 1b/ CD18 (Mac-1) up-regulation and migration to the CC chemokine CCL3 (MIP-1alpha) on human neutrophils through defined signalling pathways. Cell Signal. 2008;20(3):557-68.

28. Goransson M, Rojnik Z, Thorn K, Ost K, Delaney S. Macrophage-epithelia crosstalk regulates mucin expression in human bronchial epithelial cells [abstract]. Am J Respir Crit Care Med. 2018;197:A2920.
29. Andelid K, Andersson A, Öst K, Vanfleteren L, Göransson M. Les macrophages de mucus dans la bronchite chronique sont résistants aux corticostéroïdes et dirigent la production épithéliale de mucine par TNFa [abstract]. Rev Mal Respir Actual. 2020;12(1):96.

30. Jones PW, Harding G, Berry P, Wiklund I, Chen WH, Kline LN. Development and first validation of the COPD Assessment Test. Eur Respir J. 2009;34(3):648-54

31. Weiszhar Z, Horvath I. Induced sputum analysis: step by step. Breathe. 2013:9(4):300-6.

32. Hedenstrom H, Malmberg P, Agarwal K. Reference values for lung function tests in females. Regression equations with smoking variables. Bull Eur Physiopathol Respir. 1985;21(6):551-7.

33. Hedenstrom $\mathrm{H}$, Malmberg P, Fridriksson HV. Reference values for lung function tests in men: regression equations with smoking variables. Ups J Med Sci. 1986;91(3):299-310.

34. Bolling AK, Steensen TB, Alexis NE, Sikkeland LIB. Isolating and culturing of sputum macrophages: a potential ex vivo/in vitro model. Exp Lung Res. 2018;44(6):312-22.

35. Whitcutt MJ, Adler KB, Wu R. A biphasic chamber system for maintaining polarity of differentiation of cultured respiratory tract epithelial cells. Vitro Cell Dev Biol. 1988;24(5):420-8.

36. R Core Team. R: a language and environment for statistical computing. Vienna: R Foundation for Statistical Computing; 2020. http://www.Rproject.org/.

37. Thomas RA, Green RH, Brightling CE, Birring SS, Parker D, Wardlaw AJ, et al. The influence of age on induced sputum differential cell counts in normal subjects. Chest. 2004;126(6):1811-4.

38. Kim SW, Hong JS, Ryu SH, Chung WC, Yoon JH, Koo JS. Regulation of mucin gene expression by CREB via a nonclassical retinoic acid signaling pathway. Mol Cell Biol. 2007;27(19):6933-47.

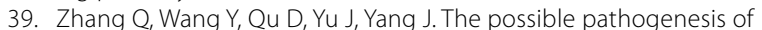
idiopathic pulmonary fibrosis considering MUC5B. Biomed Res Int. 2019;2019:9712464.

40. Gustin JA, Pincheira R, Mayo LD, Ozes ON, Kessler KM, Baerwald MR, et al. Tumor necrosis factor activates CRE-binding protein through a p38 MAPK/MSK1 signaling pathway in endothelial cells. Am J Physiol Cell Physiol. 2004;286(3):C547-55.

41. Jupp OJ, McFarlane SM, Anderson HM, Littlejohn AF, Mohamed AA, MacKay RH, et al. Type Il tumour necrosis factor-alpha receptor (TNFR2) activates c-Jun N-terminal kinase (JNK) but not mitogen-activated protein kinase (MAPK) or p38 MAPK pathways. Biochem J. 2001;359(Pt 3):525-35.

42. Livraghi-Butrico A, Grubb BR, Wilkinson KJ, Volmer AS, Burns KA, Evans $\mathrm{CM}$, et al. Contribution of mucus concentration and secreted mucins Muc5ac and Muc5b to the pathogenesis of muco-obstructive lung disease. Mucosal Immunol. 2017:10(2):395-407.

43. Silva MA, Bercik P. Macrophages are related to goblet cell hyperplasia and induce MUC5B but not MUC5AC in human bronchus epithelial cells. Lab Invest. 2012;92(6):937-48.

44. Song KS, Lee WJ, Chung KC, Koo JS, Yang EJ, Choi JY, et al. Interleukin-1 beta and tumor necrosis factor-alpha induce MUC5AC overexpression through a mechanism involving ERK/p38 mitogen-activated protein kinases-MSK1-CREB activation in human airway epithelial cells. J Biol Chem. 2003;278(26):23243-50.

45. Van Seuningen I, Pigny P, Perrais M, Porchet N, Aubert JP. Transcriptional regulation of the 11 p15 mucin genes. Towards new biological tools in human therapy, in inflammatory diseases and cancer? Front Biosci. 2001;6:D1216-34.

46. Marjanovic N, Bosnar M, Michielin F, Wille DR, Anic-Milic T, Culic O, et al. Macrolide antibiotics broadly and distinctively inhibit cytokine and chemokine production by COPD sputum cells in vitro. Pharmacol Res. 2011;63(5):389-97.

47. Alexis N, Soukup J, Ghio A, Becker S. Sputum phagocytes from healthy individuals are functional and activated: a flow cytometric comparison with cells in bronchoalveolar lavage and peripheral blood. Clin Immunol. 2000;97(1):21-32.

48. Lavrich KS, Speen AM, Ghio AJ, Bromberg PA, Samet JM, Alexis NE. Macrophages from the upper and lower human respiratory tract are metabolically distinct. Am J Physiol Lung Cell Mol Physiol. 2018;315(5):L752-64. 
49. Dunican EM, Elicker BM, Henry T, Gierada DS, Schiebler ML, Anderson $W$, et al. Mucus plugs and emphysema in the pathophysiology of airflow obstruction and hypoxemia in smokers. Am J Respir Crit Care Med. 2021;203(8):957-68.

50. Ravi AK, Khurana S, Lemon J, Plumb J, Booth G, Healy L, et al. Increased levels of soluble interleukin-6 receptor and CCL3 in COPD sputum. Respir Res. 2014;15:103.

51. Brightling CE, McKenna S, Hargadon B, Birring S, Green R, Siva R, et al. Sputum eosinophilia and the short term response to inhaled mometasone in chronic obstructive pulmonary disease. Thorax. 2005;60(3):193-8.

52. Newton R, Shah S, Altonsy MO, Gerber AN. Glucocorticoid and cytokine crosstalk: feedback, feedforward, and co-regulatory interactions determine repression or resistance. J Biol Chem. 2017;292(17):7163-72.

53. Kim RY, Pinkerton JW, Essilfie AT, Robertson AAB, Baines KJ, Brown AC, et al. Role for NLRP3 inflammasome-mediated, IL-1 beta-dependent responses in severe, steroid-resistant asthma. Am J Respir Crit Care Med. 2017;196(3):283-97.
54. Monaco C, Nanchahal J, Taylor P, Feldmann M. Anti-TNF therapy: past, present and future. Int Immunol. 2015;27(1):55-62.

55. Accortt NA, Chung JB, Bonafede M, Limone BL, Mannino DM. Retrospective analysis to describe associations between tumor necrosis factor alpha inhibitors and COPD-related hospitalizations. Int J Chron Obstruct Pulmon Dis. 2017;12:2085-94.

56. Malaviya R, Laskin JD, Laskin DL. Anti-TNFalpha therapy in inflammatory lung diseases. Pharmacol Ther. 2017;180:90-8.

57. Yousuf A, Brightling CE. Biologic drugs: a new target therapy in COPD? COPD. 2018;15(2):99-107.

\section{Publisher's Note}

Springer Nature remains neutral with regard to jurisdictional claims in published maps and institutional affiliations.
Ready to submit your research? Choose BMC and benefit from:

- fast, convenient online submission

- thorough peer review by experienced researchers in your field

- rapid publication on acceptance

- support for research data, including large and complex data types

- gold Open Access which fosters wider collaboration and increased citations

- maximum visibility for your research: over 100M website views per year

At BMC, research is always in progress.

Learn more biomedcentral.com/submissions 